Fetal Diagnosis and Therapy

\title{
Prenatal Detection and Consequences of Fetal Macrosomia
}

\author{
Christian Bamberg Larry Hinkson Wolfgang Henrich \\ Department of Obstetrics, Charité University Medical Center, Berlin, Germany
}

\author{
Key Words \\ Three-dimensional sonography $\cdot$ Birth weight $\cdot$ Prenatal \\ ultrasonography · Fetal weight estimation - Macrosomia • \\ Clinical management
}

\begin{abstract}
Macrosomia is diagnosed when excessive intrauterine fetal growth occurs and the birth weight surpasses an established limit. The causes and risk factors for fetal macrosomia are diverse. Pregnancies with fetal macrosomia are considered high risk and require intensive antenatal care. Prenatal ultrasound appears to be the best method for performing weight estimates before birth, as the correct birth weight is often underestimated when using biometric formulae to determine the fetal weight. Three-dimensional volume sonography has been shown to improve estimates of fetal weight by including limbs volumes. The recent Hart formula has been specifically developed for fetal macrosomia estimation and appears to improve accuracy. Delivery of a macrosomic baby is also high risk and should be performed in tertiary centres with experienced obstetricians.
\end{abstract}

Copyright $\odot 2012$ S. Karger AG, Basel

Macrosomia is diagnosed when excessive intrauterine growth occurs and the birth weight exceeds an established limit of either 4,000 or 4,500 g [1]. Approximately $10 \%$ of all newborns have a birth weight $>4,000 \mathrm{~g}$, and $1.5 \%$ weigh $\geq 4,500 \mathrm{~g}$ [2]. There are no nationally or in-

\section{KARGER \\ Fax +4161306 1234 \\ E-Mail karger@karger.ch}

www.karger.com
(C) 2012 S. Karger AG, Basel

$1015-3837 / 13 / 0333-0143 \$ 38.00 / 0$

Accessible online at:

www.karger.com/fdt ternationally agreed established weight limits for macrosomia; the American College of Obstetricians and Gynecologists recommends $4,500 \mathrm{~g}$ because of the marked increase in maternal and neonatal complication rates at this weight [1]. All birth weight definitions agree, however, that birth weight is independent of gestational age and consequently should not be dependent on a populationbased analysis.

This concept of the use of percentile curves issue is complicated due to the definition of large for gestational age (LGA) by some researchers when the 90 th weight percentile is exceeded, while other researchers use either the 95th percentile, the 97th percentile, or 2 standard deviations above the median as the cut-off. The advantage of using percentiles for the definition of macrosomia/LGA is the independence from gestational age. However, gender-specific values must be taken into consideration, as male newborns are on average heavier than female newborns. Furthermore, ethnicity has a significant influence on birth weight, and given the accelerated increase in birth weights in recent decades, current reference ranges must be modified [3].

\section{Diagnosis of Fetal Macrosomia by Ultrasound}

In industrialised countries the use of prenatal ultrasound has largely replaced clinical diagnosis for macrosomia. Fundal height measurement alone or in combination with symphysis-fundal height measurement results 
in fetal macrosomia diagnosis with a sensitivity of $10-$ $43 \%$ and with a positive predictive value between 28 and $53 \%[1,4]$. The low detection rate of fetal macrosomia by clinical methods may be due to abnormal fetal lie, oligoor polyhydramnios, maternal obesity, lack of experienced obstetricians, or an inconsistently defined fixed point of the fundus. A current study showed that ultrasound measurement of fetal abdominal circumference (AC) detects high and low fetal weights better than clinical examination based on the fundal height in routine practice [5]. Ultrasound allows accurate and reliable measurement of bone length and fetal body circumference [6]; thus, prenatal sonography appears to be better suited than clinical methods for performing weight estimates before birth. However, it remains problematic as the fetus has an irregular three-dimensional body of varying density and tissue composition.

If only one fetal measurement for the detection of macrosomia were to be required, then the most reliable would be the AC. The correct representation has a deciding influence on the measurement, and therefore an axial crosssectional view must be obtained. The kidneys should not be visible, and only one pair of ribs and the three ossification points of the vertebrae should be visible. Furthermore, according to Campbell and Wilkin [7] the correct transverse section includes the stomach, and Hansmann [8] stated that the umbilical vein should be visualised at the level of the portal sinus and not be present at any stage, otherwise a 'salami slice' will be obtained and the $\mathrm{AC}$ will be overestimated (fig. 1). The $\mathrm{AC}$ is measured at the outer surface of the skin line, either directly with the automatic elliptical circumference measure or calculated from perpendicular linear measurements, usually the transverse abdominal diameter (TAD) and the anteroposterior abdominal diameter (APAD; $\mathrm{AC}=1.57 \times$ (APAD + TAD); fig. 2) [9]. Dudley and Chapman [10] suggested that all fetal ACs should be measured prenatally with recent point-to-point methods that have the advantages of both trace and ellipse-fitting methods. In contrast, Kehl et al. [11] found a slight advantage for the automatic elliptical circumference measurement method.

Sonographers should keep in mind that fetal AC has the greatest impact on weight estimation. There are several publications assessing the $\mathrm{AC}$ for detecting fetal macrosomia $[12,13]$. A sonographic $A C$ of $\geq 35 \mathrm{~cm}$ at the due date has a $93 \%$ positive predictive value for birth weight $>4,000 \mathrm{~g}$ [14]. Fetal ultrasound provides a collection of biometric data, such as the biparietal diameter (BPD), the head circumference (HC), and the femur length (FL) which are also used to estimate the fetal weight. The most

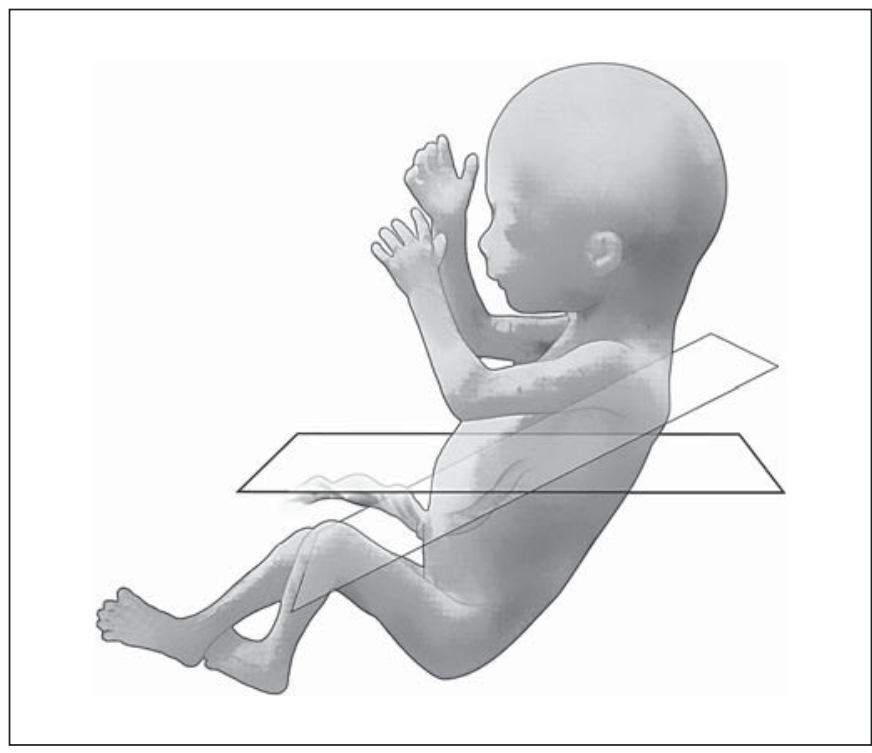

Fig. 1. Schematic representation of the correct axial plane view for the $\mathrm{AC}$ of the fetus. Along the umbilical vein is the so-called 'salami slice,' which makes the AC appear larger.

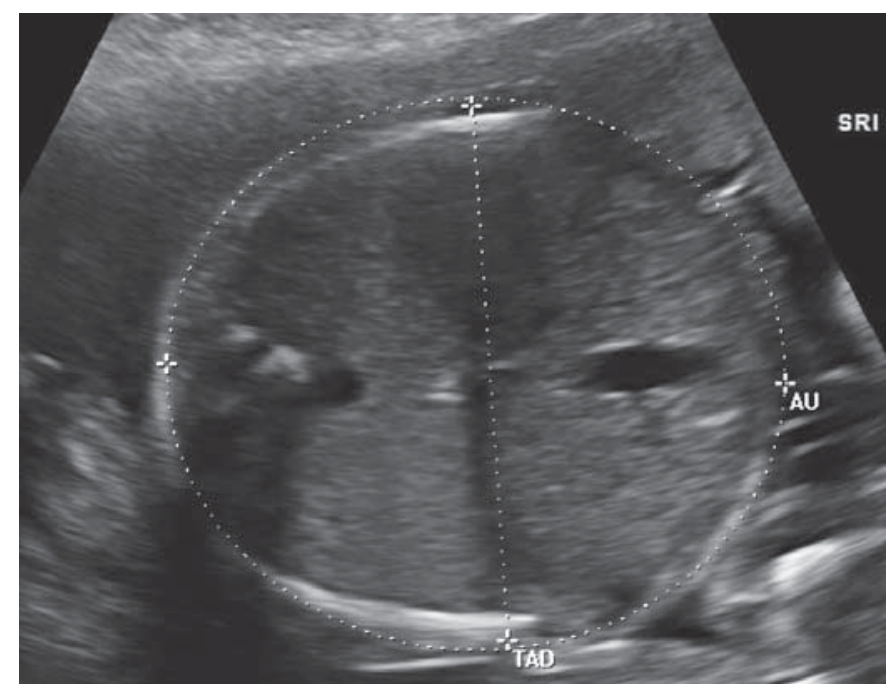

Fig. 2. Correct transverse ultrasound section for measurement of the AC.

widely used formulae are the Shepard et al. [15] and Hadlock et al. [16] formulae, which are preinstalled in most ultrasound machines. However, there is a variety of approximately three dozen defined formulae to estimate fetal weight, which may reflect a weakness of the method [17].

In comparison with other formulae, the Hadlock formula I (BPD, HC, AC, FL) has the smallest mean absolute 
error of $8.6 \%$ [18]. The pooled likelihood ratio from 63 studies was 5.9 for the detection of fetal macrosomia (birth weight $>4,000 \mathrm{~g}$ ) as determined by biometric formulae. A sonographic fetal $\mathrm{AC} \geq 36 \mathrm{~cm}$ raised the likelihood ratio to 6.9 but when the 90th percentile of the AC was used as the limit, the likelihood ratio dropped to 4.2 [19]. Another review [20] of the sonographic diagnosis of fetal macrosomia ( $\geq 4,000 \mathrm{~g}$ ) reported that the sensitivity varied from 12 to $75 \%$ and the specificity from 68 to $99 \%$ when different formulae for weight estimation were used. These formulae are perhaps better suited to normally developing fetuses than those experiencing macrosomic growth. For example, one study demonstrated that when birth weight was $>4,500 \mathrm{~g}$, the absolute error rate was $12.6 \%$; this error rate fell to $8.4 \%$ when the real birth weight was $<4,500 \mathrm{~g}$ [21]. In another study, only $50 \%$ of the weight calculations were within a $10 \%$ error rate, and when all fetal weight estimates were considered, $74 \%$ had a maximum of $10 \%$ deviation from the true birth weight [22].

The real birth weight is often underestimated when using biometric formulae to determine the estimate the fetal weight $[6,23]$. Kurmanavicius et al. [24] published a comparison of five formulas for fetal weight estimation in 5,612 newborns. Three formulae tend to underestimate large fetuses, with only the Shepard and Merz formulae generally overestimating the fetal weight and both Hadlock formulas I (BPD, HC, AC, FL) and II (AC, FL) providing the most stable results in all birth-weight groups. The Merz formula had the smallest range and smallest mean difference for fetal weights $>4,000 \mathrm{~g}$, an observation corroborated by Siemer et al. [25], who found that for fetuses $>4,000 \mathrm{~g}$, the Merz regression formula was associated with the lowest absolute percentage error and was the only formula with a mean absolute percentage error close to $7 \%$. This positive explanation may be due to the Merz formula's inclusion of the BPD and not the HC, which can be measured more precisely in late pregnancy. A new Hart formula, which included fetal biometry and maternal weight, was retrospectively compared with seven widely accepted weight formulae in 424 singleton fetuses $>4,000$ g; $77.9 \%$ of estimates fell within $\pm 5 \%$ of the actual weight at birth, $97.1 \%$ within $\pm 10 \%$, and $100 \%$ within $\pm 15-20 \%$, and compared with other formulae, the new formula exhibited the smallest mean error, the smallest mean percentage error, and the lowest mean absolute percentage error [26]. A more recent study demonstrated that the Hart formula was the most accurate of 36 formulae, and the frequency distribution of the differences between estimated fetal weight and birth weight was only slightly lower than the original data; however, the new Hart for-

Prenatal Detection and Consequences of Fetal Macrosomia mula detected all fetuses $>4,000 \mathrm{~g}$ but none of the $29 \mathrm{fe}$ tuses $>4,500 \mathrm{~g}$. The highest detection rate for fetuses $>4,500$ g was achieved with the Hadlock IV formula (HC, AC, FL) (74.5\%), but at a false positive rate of 31.5\% [27]. To overcome the problem that weight formulas designed for macrosomic fetuses bear the risk to be accidently used in with a birth weight $<4,000 \mathrm{~g}$, Kehl et al. [28] developed a formula for optimal fetal weight estimation with an AC $\geq 36 \mathrm{~cm}$. Furthermore, in order to increase the accuracy of the fetal estimated weight, serial biometric measurements could be used to generate an individual antenatal growth curve. Repeated measurement of fetal AC led to prediction of a birth weight above the 90th percentile with $84 \%$ sensitivity and $100 \%$ specificity [29].

Innovations in sonographic imaging in the late 1990s made three-dimensional views of fetal structures possible. It was hoped that this advance would lead to more accurate fetal weight estimations, as fetal weight was thought to be directly proportionate to fetal volume [30]. Chang et al. [31] and Liang et al. [32] were pioneers using three-dimensional ultrasound for fetal limb volumetry. Schild and co-workers [33-35] determined that the best formula for diagnosing fetal macrosomia appears to be a combination of two- and three-dimensional biometrics:

Fetal estimated weight $=-1,478.557+7.242 \times$ thigh volume $+13.309 \times$ upper-arm volume $+852.998 \times \log _{10}$ abdominal volume $+0.526 \times \mathrm{BPD}^{3}$

This calculation allows the mean absolute error to be reduced by $6-7 \%$, but three-dimensional ultrasound is time-consuming and not widely available. Additionally, the study was limited firstly by the small sample size of macrosomic fetuses and secondly by the heterogeneous study population. These limitations are not ideal for the evaluation of birth weight estimation accuracy at the upper end of the weight scale.

Another factor is that body composition is ignored by all formulae for fetal weight estimation, for example the subcutaneous fatty tissue on the upper arm [36], the shoulder [37], the thigh [38], or the abdomen of the fetus [39] can be measured. It is argued that, in comparison to conventional biometric formulae for estimated fetal weight, the addition of the degree of soft tissue provides no additional benefit for antenatal macrosomia detection [40]. Conversely, Lee et al. [41, 42] recently showed that the precision of fetal weight estimation improved following addition of fractional limb volume measurements to conventional two-dimensional biometry; the percentage of neonatal body fat was highly correlated with fractional thigh volume during the late third trimester.

Fetal Diagn Ther 2013;33:143-148 
In contrast, a research team with Nicolaides and colleagues [43] recently published the aspect of first-trimester prediction of macrosomia. They analysed the data of 33,602 pregnancies. The birth of macrosomic neonates was related to certain maternal characteristics (racial origin, weight, height, previous delivery of macrosomic neonates, smoking and history of chronic hypertension and diabetes mellitus) and the results of first-trimester markers (nuchal translucency, $\beta-H C G$, PAPP-A). Fetal nuchal translucency, serum $\beta-\mathrm{HCG}$ and PAPP-A were significantly higher in macrosomic than in the non-macrosomic neonates. The combined model could detect about $34 \%$ of women who delivered macrosomic newborns at a false positive rate of $10 \%$.

Finally, various factors limit the accuracy of ultrasound for the detection of antenatal fetal macrosomia [6], including: suboptimal views with oligohydramnios, maternal obesity, multiple pregnancies or unfavourable fetal lie; a lack of experienced examiners; outdated ultrasound machines, and fetal anomalies such as gastroschisis, omphalocoele, and hydrocephalus that lead to changes in biometric measurements. The error in sonographic estimation of fetal weight is dependent on the actual birth weight, and even with experienced examiners can be up to $25 \%$ [44]. Accuracy is also compromised by large intra- and inter-observer variabilities, and therefore measurement techniques should be standardised during ultrasound training. To reduce the variability in estimated fetal weight formulae such as averaging of multiple measurements, improvements in image quality, uniform calibration of equipment, and regular auditing of measurements are required [6].

\section{Practical Aspects of the Clinical Management of the Macrosomic Fetus}

There is no standardised algorithm for performing antenatal monitoring of fetal macrosomia. Since the estimated fetal weight is poorly predictive, it is sensible to perform regular ultrasound examinations. Fetal growth can only be depicted by serial measurements over the course of a pregnancy. In particular, care should be taken if the fetus goes out of its individual growth percentile. It is further recommended that at least 2 weeks occur between ultrasound measurements and if possible the same sonographer should perform the examination. Pregnancies with fetal macrosomia are high-risk pregnancies; macrosomic fetuses with birth weights between 4,500 and 4,999 g exhibited a significantly higher rate of intrauterine death [45].
Delivery of a macrosomic baby is high risk and despite the lack of evidence they should be performed in tertiary referral centres with experienced obstetricians. Shoulder dystocia represents the most serious complication associated with fetal macrosomia, with consequent neuroplexus injury [46], clavicular fracture, or asphyxia [47]. The odds ratio for shoulder dystocia is 21 for birth weights $>4,500$ g compared with normal birth weight.

The perinatal mortality rate had an odds ratio of 2.3 when the birth weight was over the 97th percentile [48], and newborns with birth weights $>4,500 \mathrm{~g}$ had a perinatal mortality rate double that of normal-weight newborns [49]. Additionally, birth weights $>4,000$ g carry a double the risk of postpartum haemorrhage of $>1,000 \mathrm{ml}$ [50], and pregnant patients with known fetal macrosomia $(4,000-4,500 \mathrm{~g})$ should be counselled regarding the 4.5fold increased risk of fourth-degree perineal tears [51].

In suspected fetal macrosomia the best mode of delivery is still being debated. In principle the three choices of induction of labour, expectant management or elective caesarean delivery are well known. There are conflicting results about the advantage of labour induction. A Cochrane analysis and a systematic review stated that labour induction for suspected fetal macrosomia results in an increased caesarean delivery rate without improving perinatal outcomes [52, 53]. Very recently, Cheng et al. [54] found in a retrospective setting of known birth weight that induction of labour may reduce the risk of caesarean delivery compared with expectant management. Elective caesarean delivery in suspected fetal macrosomia has been proposed to prevent birth trauma and labour dystocia. Most newborns and mothers have a favourable outcome when undergoing a trial of labour, whereas 3,700 women with an estimated fetal weight of 4,500 g would need to have an elective caesarean delivery to prevent one case of permanent brachial plexus injury [55]. The patient's obstetric history, her progress during labour, and other evidence of fetopelvic disproportion should be taken into account when individually counselling about the mode of delivery by suspected fetal macrosomia.

In conclusion, there is still a lack of precision of antenatal diagnosis of macrosomia using ultrasonographic estimates of fetal weight. In this era of modern obstetrics, it is important, from a practice-oriented clinical perspective, not only to correctly diagnose fetal macrosomia but also to predict the associated complications such as shoulder dystocia and palsy. The best way to manage fetal overgrowth is to prevent it $[56,57]$. 


\section{References}

1 American College of Obstetricians and Gynecologists: ACOG Practice Bulletin Fetal Macrosomia, 2000.

-2 Ventura SJ, Martin JA, Curtin SC, Mathews TJ, Park MM: Births: final data for 1998. Natl Vital Stat Rep 2000;48:1-100.

-3 Johar R, Rayburn W, Weir D, Eggert L: Birth weights in term infants. A 50-year perspective. J Reprod Med 1988;33:813-816.

4 O'Reilly-Green C, Divon M: Sonographic and clinical methods in the diagnosis of macrosomia. Clin Obstet Gynecol 2000;43: 309-320.

5 Kayem G, Grange G, Breart G, Goffinet F: Comparison of fundal height measurement and sonographically measured fetal abdominal circumference in the prediction of high and low birth weight at term. Ultrasound Obstet Gynecol 2009;34:566-571.

6 Dudley NJ: A systematic review of the ultrasound estimation of fetal weight. Ultrasound Obstet Gynecol 2005;25:80-89.

7 Campbell S, Wilkin D: Ultrasonic measurement of fetal abdomen circumference in the estimation of fetal weight. Br J Obstet Gynaecol 1975;82:689-697.

8 Hansmann M: Ultraschallbiometrie im II. und III. Trimester der Schwangerschaft. Gynäkologe 1976;9:133-155.

-9 Salomon LJ, Alfirevic Z, Berghella V, Bilardo C, Hernandez-Andrade E, Johnsen SL, et al: Practice guidelines for performance of the routine mid-trimester fetal ultrasound scan. Ultrasound Obstet Gynecol 2011;37:116126.

10 Dudley NJ, Chapman E: The importance of quality management in fetal measurement. Ultrasound Obstet Gynecol 2002;19:190196.

11 Kehl S, Zaiss I, Freiburg F, Speierer A, Sutterlin M, Siemer J: Comparison of different sonographic methods to determine fetal abdominal circumference. Fetal Diagn Ther 2010;28:201-206

12 Henrichs C, Magann EF, Brantley KL, Crews $\mathrm{JH}$, Sanderson M, Chauhan SP: Detecting fetal macrosomia with abdominal circumference alone. J Reprod Med 2003;48:339-342.

13 Loetworawanit R, Chittacharoen A, Sututvoravut $S$ : Intrapartum fetal abdominal circumference by ultrasonography for predicting fetal macrosomia. J Med Assoc Thai 2006;89(suppl 4):S60-S64.

14 Jazayeri A, Heffron JA, Phillips R, Spellacy WN: Macrosomia prediction using ultrasound fetal abdominal circumference of 35 centimeters or more. Obstet Gynecol 1999; 93:523-526.

-15 Shepard MJ, Richards VA, Berkowitz RL, Warsof SL, Hobbins JC: An evaluation of two equations for predicting fetal weight by ultrasound. Am J Obstet Gynecol 1982;142: $47-54$.
16 Hadlock FP, Harrist RB, Sharman RS, Deter RL, Park SK: Estimation of fetal weight with the use of head, body, and femur measurements - a prospective study. Am J Obstet Gynecol 1985; 151:333-337.

17 Combs CA, Rosenn B, Miodovnik M, Siddiqi TA: Sonographic EFW and macrosomia: is there an optimum formula to predict diabetic fetal macrosomia? J Matern Fetal Med 2000;9:55-61.

18 Pinette MG, Pan Y, Pinette SG, Blackstone J, Garrett J, Cartin A: Estimation of fetal weight: mean value from multiple formulas. J Ultrasound Med 1999;18:813-817.

19 Coomarasamy A, Connock M, Thornton J, Khan KS: Accuracy of ultrasound biometry in the prediction of macrosomia: a systematic quantitative review. BJOG 2005;112: 1461-1466.

20 Chauhan SP, Grobman WA, Gherman RA, Chauhan VB, Chang G, Magann EF, et al: Suspicion and treatment of the macrosomic fetus: a review. Am J Obstet Gynecol 2005; 193:332-346.

21 Asylman O, Ouzounian JG, Kjos SL: The accuracy of intrapartum ultrasonographic fetal weight estimation in diabetic pregnancies. Am J Obstet Gynecol 1997;177:503-506.

-22 Benacerraf BR, Gelman R, Frigoletto FD Jr: Sonographically estimated fetal weights: accuracy and limitation. Am J Obstet Gynecol 1988;159:1118-1121.

23 Scioscia M, Vimercati A, Ceci O, Vicino M, Selvaggi LE: Estimation of birth weight by two-dimensional ultrasonography: a critical appraisal of its accuracy. Obstet Gynecol 2008;111:57-65.

24 Kurmanavicius J, Burkhardt T, Wisser J, Huch R: Ultrasonographic fetal weight estimation: accuracy of formulas and accuracy of examiners by birth weight from 500 to 5,000 g. J Perinat Med 2004;32:155-161.

25 Siemer J, Egger N, Hart N, Meurer B, Muller A, Dathe O, et al: Fetal weight estimation by ultrasound: comparison of 11 different formulae and examiners with differing skill levels. Ultraschall Med 2008;29:159-164.

-26 Hart NC, Hilbert A, Meurer B, Schrauder M, Schmid M, Siemer J, et al: Macrosomia: a new formula for optimized fetal weight estimation. Ultrasound Obstet Gynecol 2010;35: 42-47.

27 Hoopmann M, Abele H, Wagner N, Wallwiener D, Kagan KO: Performance of 36 different weight estimation formulae in fetuses with macrosomia. Fetal Diagn Ther 2010;27: 204-213.

28 Kehl S, Korber C, Hart N, Goecke TW, Schild RL, Siemer J: New sonographic method for fetuses with a large abdominal circumference improves fetal weight estimation. Ultraschall Med 2012;33:265-269.
29 Hedriana HL, Moore TR: A comparison of single versus multiple growth ultrasonographic examinations in predicting birth weight. Am J Obstet Gynecol 1994;170:1600 1604.

30 Combs CA, Singh NB, Khoury JC: Elective induction versus spontaneous labor after sonographic diagnosis of fetal macrosomia. Obstet Gynecol 1993;81:492-496.

-31 Chang FM, Liang RI, Ko HC, Yao BL, Chang $\mathrm{CH}, \mathrm{Yu} \mathrm{CH}$ : Three-dimensional ultrasoundassessed fetal thigh volumetry in predicting birth weight. Obstet Gynecol 1997;90:331339 .

32 Liang RI, Chang FM, Yao BL, Chang CH, Yu $\mathrm{CH}$, Ko HC: Predicting birth weight by fetal upper-arm volume with use of three-dimensional ultrasonography. Am J Obstet Gynecol 1997; 177:632-638.

33 Schild RL, Fimmers R, Hansmann M: Can $3 \mathrm{D}$ volumetric analysis of the fetal upper arm and thigh improve conventional 2D weight estimates? In German. Ultraschall Med 1999;20:31-37.

34 Schild RL, Fimmers R, Hansmann M: Fetal weight estimation by three-dimensional ultrasound. Ultrasound Obstet Gynecol 2000; 16:445-452.

35 Hasenoehrl G, Pohlhammer A, Gruber R, Staudach A, Steiner H: Fetal weight estimation by $2 \mathrm{D}$ and $3 \mathrm{D}$ ultrasound: comparison of six formulas. Ultraschall Med 2009;30: 585-590.

36 Sood AK, Yancey M, Richards D: Prediction of fetal macrosomia using humeral soft tissue thickness. Obstet Gynecol 1995;85:937940

37 Mintz MC, Landon MB, Gabbe SG, Marinelli DL, Ludmir J, Grumbach K, et al: Shoulder soft tissue width as a predictor of macrosomia in diabetic pregnancies. Am J Perinatol 1989;6:240-243.

38 Hill LM, Guzick D, Boyles D, Merolillo C, Ballone A, Gmiter P: Subcutaneous tissue thickness cannot be used to distinguish abnormalities of fetal growth. Obstet Gynecol 1992;80:268-271.

39 Petrikovsky BM, Oleschuk C, Lesser M, Gelertner N, Gross B: Prediction of fetal macrosomia using sonographically measured abdominal subcutaneous tissue thickness. J Clin Ultrasound 1997;25:378-382.

40 Chauhan SP, West DJ, Scardo JA, Boyd JM, Joiner J, Hendrix NW: Antepartum detection of macrosomic fetus: clinical versus sonographic, including soft-tissue measurements. Obstet Gynecol 2000;95:639-642.

41 Lee W, Balasubramaniam M, Deter RL, Hassan SS, Gotsch F, Kusanovic JP, et al: Fractional limb volume - a soft tissue parameter of fetal body composition: validation, technical considerations and normal ranges during pregnancy. Ultrasound Obstet Gynecol 2009;33:427-440. 
42 Lee W, Balasubramaniam M, Deter RL, Yeo L, Hassan SS, Gotsch F, et al: New fetal weight estimation models using fractional limb volume. Ultrasound Obstet Gynecol 2009;34:556-565.

43 Poon LC, Karagiannis G, Stratieva V, Syngelaki A, Nicolaides KH: First-trimester prediction of macrosomia. Fetal Diagn Ther 2011;29:139-147.

44 Manning F: Intrauterine Growth Retardation. Norwalk, Appleton \& Lange, 1995.

45 Zhang X, Decker A, Platt RW, Kramer MS: How big is too big? The perinatal consequences of fetal macrosomia. Am J Obstet Gynecol 2008;198:517.e1-6.

-46 Gherman RB, Ouzounian JG, Goodwin TM: Obstetric maneuvers for shoulder dystocia and associated fetal morbidity. Am J Obstet Gynecol 1998;178:1126-1130.

-47 Baskett TF, Allen AC: Perinatal implications of shoulder dystocia. Obstet Gynecol 1995; 86:14-17.
48 Lackman F, Capewell V, Richardson B, daSilva O, Gagnon R: The risks of spontaneous preterm delivery and perinatal mortality in relation to size at birth according to fetal versus neonatal growth standards. Am J Obstet Gynecol 2001;184:946-953.

49 Modanlou HD, Dorchester WL, Thorosian A, Freeman RK: Macrosomia - maternal, fetal, and neonatal implications. Obstet Gynecol 1980;55:420-424.

50 Stones RW, Paterson CM, Saunders NJ: Risk factors for major obstetric haemorrhage. Eur J Obstet Gynecol Reprod Biol 1993;48:15-18.

51 Stotland NE, Caughey AB, Breed EM, Escobar GJ: Risk factors and obstetric complications associated with macrosomia. Int J Gynaecol Obstet 2004;87:220-226.

52 Irion O, Boulvain M: Induction of labour for suspected fetal macrosomia. Cochrane Database Syst Rev 2000;CD000938.
53 Sanchez-Ramos L, Bernstein S, Kaunitz AM: Expectant management versus labor induction for suspected fetal macrosomia: a systematic review. Obstet Gynecol 2002;100: 997-1002.

54 Cheng YW, Sparks TN, Laros RK Jr, Nicholson JM, Caughey AB: Impending macrosomia: will induction of labour modify the risk of caesarean delivery? BJOG 2012;119:402409.

55 Rouse DJ, Owen J, Goldenberg RL, Cliver SP: The effectiveness and costs of elective cesarean delivery for fetal macrosomia diagnosed by ultrasound. JAMA 1996;276:1480-1486.

56 Althuizen E, van Poppel MN, Seidell JC, van der Wijden C, van Mechelen W: Design of the New Life(style) study: a randomised controlled trial to optimise maternal weight development during pregnancy. BMC Public Health 2006;6:168.

57 Sandmire HF, Woolley RJ: Macrosomia: can we prevent big problems with big babies? Birth 1998;25:263-267. 